\begin{tabular}{|c|c|c|c|c|c|c|}
\hline \multirow{4}{*}{ Impact Factor: } & ISRA (India) & $=3.117$ & SIS (USA) & $=0.912$ & ICV (Poland) & $=6.630$ \\
\hline & ISI (Dubai, UAE & $=0.829$ & РИНЦ (Russia) & $=0.156$ & PIF (India) & $=1.940$ \\
\hline & GIF (Australia) & $=0.564$ & ESJI (KZ) & $=8.716$ & IBI (India) & $=4.260$ \\
\hline & JIF & $=1.500$ & SJIF (Morocco) & $=5.667$ & OAJI (USA) & $=0.350$ \\
\hline
\end{tabular}

\section{SOI: $1.1 /$ TAS $\quad$ DOI: $10.15863 /$ TAS International Scientific Journal Theoretical \& Applied Science}

p-ISSN: 2308-4944 (print) e-ISSN: 2409-0085 (online)

Year: $2019 \quad$ Issue: $05 \quad$ Volume: 73

Published: $30.05 .2019 \quad \underline{\text { http://T-Science.org }}$

SECTION 9. Chemistry and chemical technology
QR - Issue

QR - Article

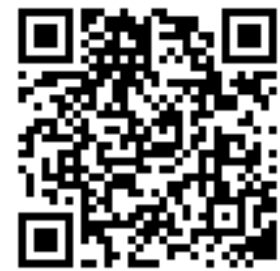

Doctor of Chemical and Biological Engineering, Associated Professor, Faculty of Technological Engineering, Department of Chemical and Environmental Technologies, Akaki Tsereteli State University, Kutaisi, Georgia. (+995) 599535680 m.tatvidze@yahoo.com

\title{
STUDY OF DRIED ROSEHIP WITH THE METHOD OF HIGH- PRESSURE LIQUID CHROMATOGRAPHY
}

Abstract: The article presents the research data of rose hip, common in the high mountainous region Racha from Georgia, using high pressure liquid chromatography. The study was subject to dried ripe rose hips. Certain phenolic compounds of plant materials, as well as organic acids, in particular, ascorbic acid, have been determined. The corresponding chromatograms are presented, as well as the chromatographic characterization of the biologically active substrates of the sample. The presence of a large amount of flavonoids and vitamin $C$ contributes to the high biological activity of wild ripe rose hips.

Key words: Rosehip, ascorbic acid, flavonoids, liquid chromatography.

Language: Russian

Citation: Tatvidze, M. L. (2019). Study of dried rosehip with the method of high-pressure liquid chromatography. ISJ Theoretical \& Applied Science, 05 (73), 375-378.

Soi: http://s-o-i.org/1.1/TAS-05-73-55 Doi: crossef https://dx.doi.org/10.15863/TAS.2019.05.73.55

\section{ИССЛЕДОВАНИЕ СУШЕНЫХ ПЛОДОВ ШИПОВНИКА МЕТОДОМ ЖИДКОСТНОЙ ХРОМАТОГРАФИЙ ВЫСОКОГО ДАВЛЕНИЯ}

Аннотация: В статье приведены данные исследования распространенного в высокогорном районе Рача Грузии шиповника - Rosa сапіпа методом жидкостной хроматографии высокого давления. Исследованию подлежали сушеные зрелье плоды шиповника. Определены некоторые фенольные соединения растительного сырья, а также органические кислоты, в частности, аскорбиновая кислота. Представлень соответствуюшие хроматограммы, а также хроматографическая характеристика биологически активных субстратов образца. Наличие большого количества флавоноидов и витамина $C$ способствует высокой биологической активности шиповника.

Ключевые слова: Шиповник, аскорбиновая кислота, флавоноиды, жидкостная хроматография.

\section{Introduction}

Целью работы было изучение биологически активных веществ шиповника - Rosa canina, распространенного в высокогорном районе Рача Грузии. Методом жидкостной хроматографии высокого давления исследовали сушеные зрелые плоды шиповника [1, с. 12-15; 2, с. 205-209].

Для качественного анализа фенольных соединений использовали хроматограф -Waters (USA), uv/visible Detector 2489, Binary HPLC Pump1525, хроматографическая колонка Symmetry C18, детектирование на 510 нм. Подвижная фаза муравьиная кислота 5\% А) и метанол (В), линейный градиент; скорость растворителя 1мл/мин, количество исследуемого образца $20 \mu 1$.

\section{Materials and Methods}

Методом жидкостной хроматографии высокого давления определены количественные и качественные показатели некоторых биологически активных веществ сушеных плодов шиповника. На рис. 1 представлена хроматограмма флавоноидных гликозидов исследуемого материала, а в таблице 1 представлена хроматографическая характеристика флавоноидных гликозидов 


\begin{tabular}{|c|c|c|c|c|c|c|}
\hline \multirow{4}{*}{ Impact Factor: } & ISRA (India) & $=3.117$ & SIS (USA) & $=0.912$ & ICV (Poland) & $=6.630$ \\
\hline & ISI (Dubai, UAE & $=0.829$ & РИНЦ (Russia) & $=0.156$ & PIF (India) & $=1.940$ \\
\hline & GIF (Australia) & $=0.564$ & ESJI (KZ) & $=8.716$ & IBI (India) & $=4.260$ \\
\hline & JIF & $=1.500$ & SJIF (Morocco) & $=5.667$ & OAJI (USA) & $=0.350$ \\
\hline
\end{tabular}

образца. Как видно, доминирует кемпферол-3-0-

глюкозид и его изомеры.

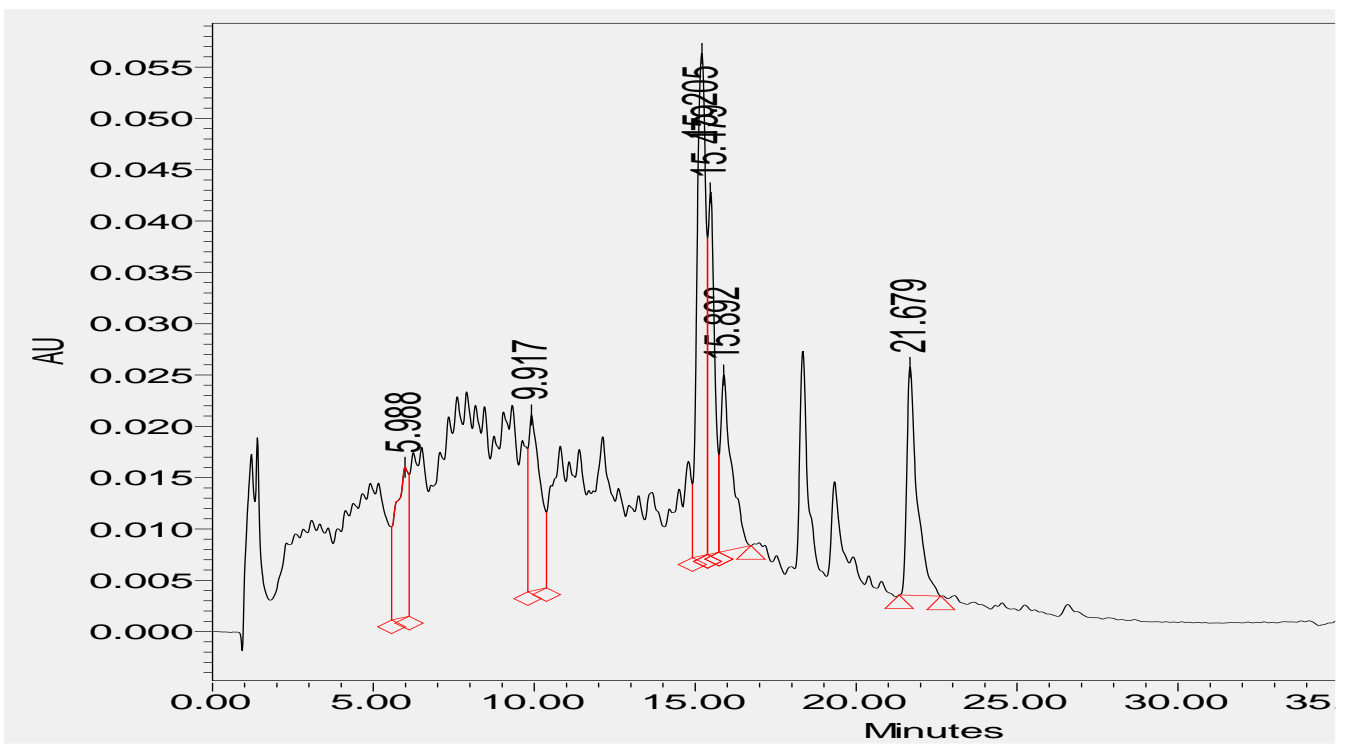

Рис. 1. Жидкостная хроматография высокого давления сушеных плодов шиповника, детектирование 370 нм

- кемпферол-3-0-глюкозид

Таблица 1. Хроматографическая характеристика флавоноидных гликозидов мякоти сушеных плодов шиповника

\begin{tabular}{|l|l|l|l|l|}
\hline № & Наименование & Время удерживания & Площадь & \% площади \\
\hline 1 & & 5.988 & 403034 & 12.66 \\
\hline 2 & & 9.917 & 437550 & 13.74 \\
\hline 3 & Кемпферол-3-0-глюкозид & 15.205 & 928020 & 29.15 \\
\hline 4 & & 15.479 & 510937 & 16.05 \\
\hline 5 & & 15.892 & 409854 & 12.87 \\
\hline 6 & & 21.679 & 494333 & 15.53 \\
\hline
\end{tabular}

В таблице 2 представлены количества некоторых фенольных соединений зрелых плодов шиповника. Методом жидкостной хроматографии высокого давления исследовали плоды шиповника зеленовато-желтого, желтоватооранжевого и оранжевых цветов, а также количественно определены те же соединения в сушеных плодах шиповника.

Таблица 2. Количество фенольных соединений шиповника (мг/кг)

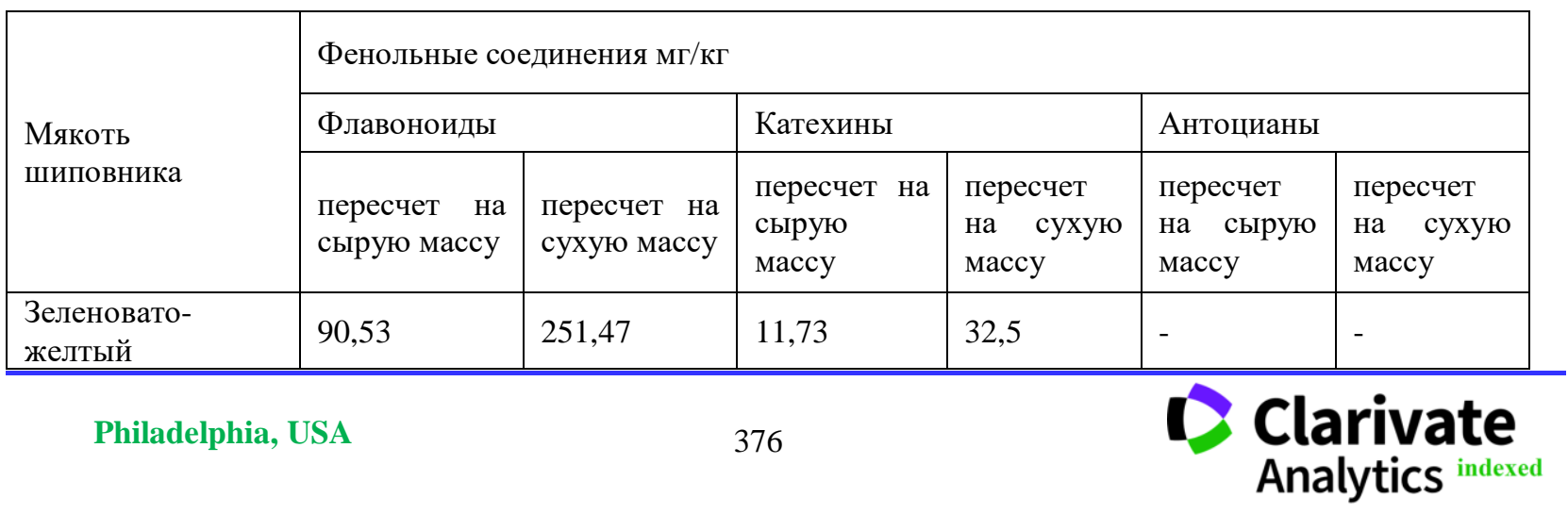




\begin{tabular}{|c|c|c|c|c|c|c|}
\hline \multirow{4}{*}{ Impact Factor: } & ISRA (India) & $=3.117$ & SIS (USA) & $=0.912$ & ICV (Poland) & $=6.630$ \\
\hline & ISI (Dubai, UAI & $=0.829$ & РИНЦ (Russia & $=0.156$ & PIF (India) & $=1.940$ \\
\hline & GIF (Australia) & $=0.564$ & ESJI (KZ) & $=8.716$ & IBI (India) & $=4.260$ \\
\hline & JIF & $=1.500$ & SJIF (Morocce & $=5.667$ & OAJI (USA) & $=0.350$ \\
\hline
\end{tabular}

\begin{tabular}{|l|l|l|l|l|l|l|}
\hline $\begin{array}{l}\text { Желтовато- } \\
\text { оранжевый }\end{array}$ & 185,94 & 516,5 & 68,25 & 189,05 & - & - \\
\hline Оранжевый & 111,56 & 309,88 & 236,6 & 655,4 & 540,0 & 1500,0 \\
\hline Сушенный плод & 253,8 & 288,4 & 40,21 & 45,7 & 1174,27 & 1334,4 \\
\hline
\end{tabular}

В плодах шиповника большое количество разных органических кислот, такие как фенилкарбоновые кислоты, аминокислоты, лимонная кислота, яблочная кислота и др. [3, с. 141-148; 4, с. 108-113; 5, 35-38]. Но особо ценным лекарственным растением шиповник является изза наличие огромного количества L-аскорбиновой кислоты - витамина С. Количество витамина С зависит от сорта, места и времени сбора шиповника [6, с. 62-68; 7, с. 117-123]. Следует отметить, что L-аскорбиновая кислота шиповника отличается устойчивостью и при переработке плодов его количество сохраняется практически без изменений.

Детектирование аскорбиновой кислоты (витамина С) проводилось при длине волны 254 нм, подвижная фаза метанол 20\%, $\mathrm{pH} 2,6$.

На рис. 2 представлена хроматограмма шиповника, а в таблице 3 представлена хроматографическая характеристика витамина С в сушеных плодах шиповника.

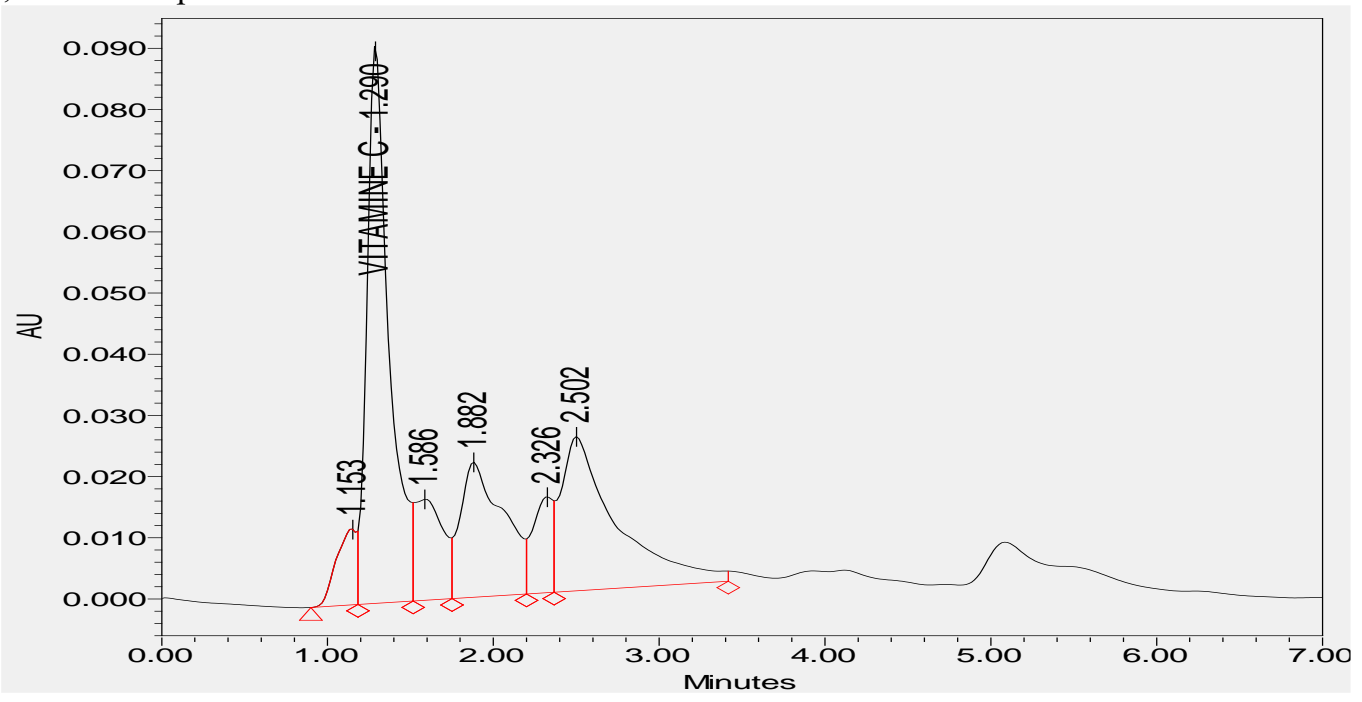

Рис. 2. Жидкостная хроматография высокого давления сушеных плодов шиповника, детектирование 274 нм

- аскорбиновая кислота

Таблица 3. Хроматографическая характеристика L-аскорбиновой кислоты шиповника

\begin{tabular}{|l|l|l|l|l|l|l|l|}
\hline № & Наименование & $\begin{array}{l}\text { Время } \\
\text { удерживания }\end{array}$ & Площадь & \% Площади & Высота & Количество & Единица \\
\hline 1 & & 1.153 & 105662 & 4.64 & 12292 & & \\
\hline 2 & Витамин C & 1.290 & 849680 & 37.31 & 91271 & 1550 & мг/кг \\
\hline 3 & & 1.586 & 197467 & 8.67 & 16497 & & \\
\hline 4 & & 1.882 & 401719 & 17.64 & 22068 & & \\
\hline 5 & & 2.326 & 132187 & 5.81 & 15693 & & \\
\hline 6 & & 2.502 & 590351 & 25.93 & 25206 & & \\
\hline
\end{tabular}




\begin{tabular}{|c|c|c|c|c|c|c|}
\hline \multirow{4}{*}{ Impact Factor: } & ISRA (India) & $=3.117$ & SIS (USA) & $=0.912$ & ICV (Poland) & $=6.630$ \\
\hline & ISI (Dubai, UAI & $=0.829$ & РИНЦ (Russia & $=0.156$ & PIF (India) & $=1.940$ \\
\hline & GIF (Australia) & $=0.564$ & ESJI (KZ) & $=8.716$ & IBI (India) & $=4.260$ \\
\hline & JIF & $=1.500$ & SJIF (Morocce & $=5.667$ & OAJI (USA) & $=0.350$ \\
\hline
\end{tabular}

\section{Conclusion}

Исследования показали, что плоды шиповника богаты фенольными соединениями. При правильной сушке плодов шиповника фенольный состав практически не меняется, а количество сохраняется на 80-90\%. Антоцианы, а также суммарное количество фенольных соединений в относительно высоких концентрациях обнаруживаются в краснооранжевых плодах. $45 \%$ от общего количества флавоноидов представлена кемпферол-3-0- глюкозидом. Следует отметить, что на данном этапе исследований идентификация антоцианов не проводилась [8, с. 103-108; 9, с. 265-267; 10, 32]. Также следует отметить, что по результатам наших исследований сушеная мякоть плодов шиповника из высокогорных районов Грузии сдержат внушительное количество Lаскорбиновой кислоты $(1500 \mathrm{Mг} / к \Gamma)$, что в значительной мере способствует высокой биологической активности шиповника.

\section{References:}

1. Sergunova, E. V., \& Sorokina, A. A. (2011). Issledovaniya po standartizatsii plodov shipovnika. Farmatsiya, (5), pp.12-15.

2. Checheta, O. V., Safonova, E. F., Slivkin, A. I., \& Snopov, S. V. (2011). Opredelenie flavonoidov v plodah shipovnika (Rosa sp.). Vestnik Voronezhskogo gosudarstvennogo universiteta. Seriya: Himiya. Biologiya. Farmatsiya, (1), pp.205-209.

3. Trineeva, O. V., Sinkevich A. V., \& Slivkin, A. I. (2015). Issledovanie aminokislotnogo sostava izvlecheniy iz rastitelsnyih obъektov. Himiya rastitelnogo syirya. 2 (apr. 2015), 141-148. DOI: https://doi.org/10.14258/jcprm.201502292

4. Paunović, D., et al. (2019). Assessment of Chemical and Antioxidant Properties of Fresh and Dried Rosehip (Rosa canina L.). Notulae Botanicae Horti Agrobotanici ClujNapoca, 47(1), pp.108-113.

5. Moiseev, D. V., Buzuk, G. N., \& Shelyuto, V. L. (2011). Identifikatsiya flavonoidov v rasteniyah metodom VEZhH. Himiko-farmatsevticheskiy zhurnal, 45(1), pp.35-38.
6. Czyzowska, A., Klewicka, E., Pogorzelski, E., \& Nowak, A. (2015). Polyphenols, vitamin C and antioxidant activity in wines from Rosa canina L. and Rosa rugosa Thunb. Journal of Food Composition and Analysis, 39, pp.62-68.

7. Hosni, K., et al. (2010). Fatty acid and phenolic constituents of leaves, flowers and fruits of tunisian dog rose (Rosa canina L.). Riv. Ital. Sostanze Gr, 87, pp.117-123.

8. Vanidze, M. R., Kalandia, A. G., \& Shalasvili, A.G. (2009). Flavonols connection of fruit of the feijo. Chemistry, (3), pp.103-108.

9. Tatvidze, M., \& Aleko, K. (2013). Issledovanie soderzhaniya flavonoidov $\mathrm{i}$ antotsianov $\mathrm{v}$ spelyih plodah buzinyi. Himiya rastitelnogo syirya, (4), pp.265-267.

10. Tatvidze, M., \& Shalamberidze, M. (2015). The influence of dispersion of blueberries on the yield of biologically active compounds. Scientific enquiry in the contemporary world: theoretical basics and innovative approach, p.32. 